\title{
TRANSIENT FINITE ELEMENT SIMULATION AND MICROSTRUCTURE EVOLUTION OF AA2219 WELD JOINT USING GAS TUNGSTEN ARC WELDING PROCESS
}

\author{
Sivaraman Arunkumar', Anup Kulkarni Shrikrishna', Sathiya Paulraj', \\ Kandasami Devakumaran², Subramanian Ramesh Kumar ${ }^{3}$ \\ 1 Department of Production Engineering, National Institute of Technology, Tiruchirappalli 620015, Tamilnadu, \\ India, e-mail: psathiya@nitt.edu \\ 2 Welding Research Institute, BHEL, Tiruchirappalli, Tamilnadu, India \\ ${ }^{3}$ School of Mechanical Engineering, SASTRA University, Thanjavur, Tamilnadu, India
}

Received: 2016.04.12

Accepted: 2016.07.04

Published: 2016.09.01

\begin{abstract}
In this study we focus on finite element simulation of gas tungsten arc welding (GTAW) of AA2219 aluminum alloy and the behavioral of the microstructure before and after weld. The simulations were performed using commercial COMSOL Multiphysics software. The thermal history of the weld region was studied by initially developed mathematical model. A sweep type meshing was used and transient analysis was performed for one welding cycle. The highest temperature noted was $3568{ }^{\circ} \mathrm{C}$ during welding. The welding operation was performed on $200 \times 100 \times 25 \mathrm{~mm}$ plates. Through metallurgical characterization, it was observed that a fair copper rich cellular (CRC) network existed in the weld region. A small amount of intermetallic compounds like $\mathrm{Al}_{2} \mathrm{Cu}$ is observed through the XRD pattern.
\end{abstract}

Keywords: AA2219 aluminium alloy, gas tungsten arc welding, finite element simulation, metallurgical characterization.

\section{INTRODUCTION}

AA2219 is basically an Al-Cu-Mn ternary alloy and has a unique combination of properties such as good weldability and high strength to weight ratio [1]. The alloy is extensively used in the fabrication of cryogenic tanks and pressure vessels due to its high strength, superior resistance to cracking and corrosion resistance. The AA2219 aluminium alloy contains a major alloying addition of copper and minor additions of manganese, titanium, vanadium and zirconium. Generally, the alloy is produced in the T87 temper condition (solution treatment $+7 \%$ cold working + aging) [2]. One of the drawbacks of most of the high strength $\mathrm{Al}$ alloys is that they suffer from poor weldability. However, AA2219 is an exception due to the presence of more $\mathrm{Cu}$ that helps in healing the cracks by providing extra eutectics.
A lot of studies have been carried out in order to assess the effect of copper content and the distribution of second phase intermetallic particles on the properties of AA 2219 alloy [3].

GTAW welding is one of the mostly used fabrication processes in the industry due to its wide range of applications. The gas tungsten arc welding (GTAW) process was originally developed in 1940s to weld magnesium and aluminum alloys for aircraft applications. Argon gas soon became the most widely used shield gas because of its lower cost and smoother arc. Gas tungsten arc weldment of AA2219 aluminum alloy was characterized by its microstructure, transverse shrinkage, metallurgical and mechanical properties. AA2219 alloy is widely used for fabrication of fuel tanks in Aerospace application industries. Fracture toughness of this alloy is the most important design criteria 
for some selected missile, space vehicles and aircraft [4]. This analysis shows also that, within the bounds of measured un-certainty, the prediction remains acceptable with respect to the largest mismatch revealed in temperature [12].

The use of the Finite Element Method (FEM) in product development is now well established. Its use in manufacturing processes is increasing and is part of the field of new applications in computational mechanics. The most important reason for this development is the industrial need to improve productivity and quality of products and to have better understanding of the influence of different process parameters [5]. The modeled phenomena play an important role at various stages of the production of steel parts, such as welding, heat treatment and casting, among others. The importance of these applications lies in determining the evolution of stresses and deformations to predict, for example, susceptibility to cracking and thus prevent failures during welding or even service. Furthermore, this simulation tool can be used to optimize different aspects of welding processes.

Simulation is a very powerful tool to help in understanding the factors limiting the quality of welding. A 3D finite element model of heat and fluid flow in weld pool considering free surface of the pool and traveling speed has been developed for the GTAW process. COMSOL software is also used to compute all the governing equations. The free surface of the weld pool is calculated by minimizing the total surface energy. The combined effects of surface tension gradient, buoyancy force, arc pressure, gravity to drive the fluid flow are included in our model. The deformation of the weld pool surface and the welding speed affect fluid flow, heat flow and thus temperature gradients, molten pool dimensions and the humping phenomena which occur at a high arc pressure and welding speed. Welding trials study is presented to compare our numerical results with macrograph of the molten pool [6-8].The goal of thermo-mechanical analysis is to realize the significance of simulation of arc welding using finite element method. FEM is usually preferred to monitor and predict the welding process that focused on 3D-thermo-mechanical simulation of welding process.

The buoyancy force is observed to increase with increase in electrode tip angle. Increasing the arc length decreases the buoyancy force in the weld pool. Pool convection decreases with increase in tip angle. The computed weld pool shapes are observed wide and shallow with small and narrow and deep with large electrode tip angle. The computed pool shapes are compared with the experimental results and are observed in good agreement [13]. The FEM dynamic heat source model was used to simulate the low frequency PCGTAW, which has successfully demonstrated the dynamic temperature field in the welding process. In some welding process simulation, especially for those whose dynamic characteristic is more obvious, the dynamic yielding heat source model has more advantages over the static models. The static heat source model is the special case of the dynamic heat source model, which is not varied with time [14]. The main objective of this simulation is the determination of temperatures and stresses during and after the process. Temperature distribution defines the heat affected zone where material properties are affected.

\section{EXPERIMENTAL PROCEDURE}

\section{Welding}

Two 25 mm-thick AA2219 plates were buttwelded by GTAW process. The plates were rigidly fixed to avoid distortion during welding. Double $\mathrm{V}$ groove design was used as shown in Figure 1. The welding parameters used for the present study are given in Table 1 . The welding was carried out in an automatic mode. During welding, the welding parameters such as arc voltage and welding current were measured using a digital meter fitted in the welding power source. Prior to the welding, the plates were cleaned with brush followed by acetone to remove oxide layers over faying surfaces. In the double V-groove, initially, welding was carried out on side-B followed by side-A (Figure 1). Experimental setup has been shown in Figure 2 and the base material properties are shown Table 2.

\section{Studies on weld joint characteristics}

After welding, the weld samples were subjected to X-ray diffraction technique (XRD) to determine for any surface or sub surface defects. Based on the XRD results, it was ensured that the welds had absolutely defect free joints. Then the welded samples were extracted for various metallurgical tests as per the AWS D1.2 standard. A metallography sample was prepared as per the standard metallographic technique and etched with Weck's reagent $(100 \mathrm{~mL}$ of water, $4 \mathrm{~g}$ of 
$\mathrm{KMnO}_{4}$ and $1 \mathrm{~g}$ of $\left.\mathrm{NaOH}\right)$. The scanning electron microscope (SEM) was used to characterize the various features of microstructures of weld joints.

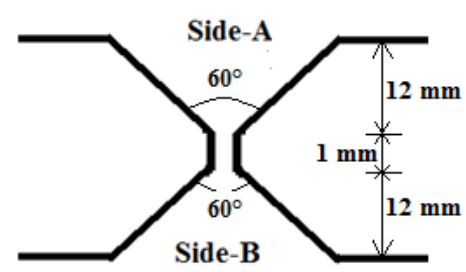

Fig. 1. Schematic diagram showing locations side-A and side- $\mathrm{B}$ of double $\mathrm{V}$ groove

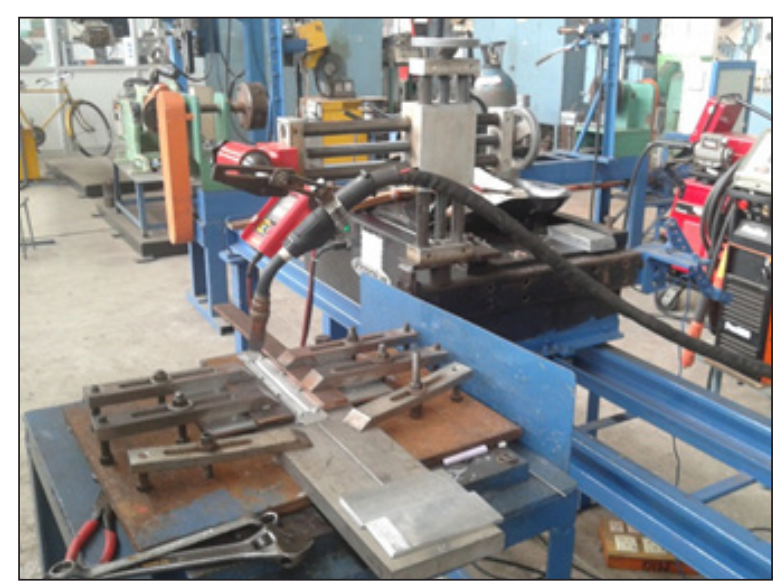

Fig. 2. Photographic view of weld joint setup
Table 1. Welding parameters used for preparation of weld joints

\begin{tabular}{|c|c|}
\hline Welding position & $1 G$ \\
\hline Welding current/A & $125-138$ \\
\hline Arc voltage/V & $10.5-11.8$ \\
\hline Welding speed $/\left(\mathrm{cm} \cdot \mathrm{min}^{-1}\right)$ & $10-11$ \\
\hline Heat input $/\left(\mathrm{kJ} \cdot \mathrm{cm}^{-1}\right)$ & $7.16-9.77$ \\
\hline $\begin{array}{l}\text { Filler wire diameter and } \\
\text { specifications }\end{array}$ & 2-2.5 mm \& ER 2319 \\
\hline Shielding gas & $\begin{array}{l}\text { Commercially pure argon at } \\
\text { gas flow rate of } 15 \mathrm{lpm}\end{array}$ \\
\hline Polarity & $A C$ \\
\hline $\begin{array}{l}\text { Tungsten electrode size } \\
\text { and specifications }\end{array}$ & $2 \%$ Zirconated \\
\hline Inter pass temperature & Less than $100^{\circ} \mathrm{C}$ \\
\hline
\end{tabular}

Table 2. Material Properties

\begin{tabular}{|l|c|}
\hline \multicolumn{1}{|c|}{ Property } & Value \\
\hline Heat capacity $(\mathrm{Cp})$ & $900[\mathrm{~J} /(\mathrm{kg}-\mathrm{K})]$ \\
\hline Density $(\rho)$ & $2700\left[\mathrm{~kg} / \mathrm{m}^{3}\right]$ \\
\hline Thermal Conductivity $(\mathrm{k})$ & $201\left[\mathrm{~W} /\left(\mathrm{m}^{*} \mathrm{~K}\right)\right]$ \\
\hline $\begin{array}{l}\text { Coefficient of thermal } \\
\text { expansion }(\alpha)\end{array}$ & $23.4 \mathrm{e}-6[1 / \mathrm{K}]$ \\
\hline Young's modulus $(\mathrm{E})$ & $69 \mathrm{e} 3 \mathrm{MPa}$ \\
\hline Poisson's ratio $(\mu)$ & 0.33 \\
\hline $\begin{array}{l}\text { Melting point temperature } \\
\text { range }\end{array}$ & $543-643^{\circ} \mathrm{C}$ \\
\hline
\end{tabular}

\section{MATHEMATICAL MODEL}

\section{The thermal model}

The following differential equation for 3D heat conduction is satisfied by the spatial and temporal temperature distribution [9]:

$$
\frac{\partial}{\partial \mathrm{x}}\left(\mathrm{k}_{\mathrm{x}} \frac{\partial \mathrm{T}}{\partial \mathrm{x}}\right)+\frac{\partial}{\partial \mathrm{y}}\left(\mathrm{k}_{\mathrm{y}} \frac{\partial \mathrm{T}}{\partial \mathrm{y}}\right)+\frac{\partial}{\partial \mathrm{z}}\left(\mathrm{k}_{\mathrm{z}} \frac{\partial \mathrm{T}}{\partial \mathrm{z}}\right)+\mathrm{Q}=\rho \mathrm{Cp}\left(\frac{\partial \mathrm{T}}{\partial \mathrm{t}}-\mathrm{v} \frac{\partial \mathrm{T}}{\partial \mathrm{x}}\right)
$$

From equation (1), where $\mathrm{T}(\mathrm{x}, \mathrm{y}, \mathrm{z}, \mathrm{t})$ is the current temperature, $\mathrm{Q}(\mathrm{x}, \mathrm{y}, \mathrm{z}, \mathrm{t})$ is the rate of internal heat generation, $\mathrm{k}_{\mathrm{x}}, \mathrm{k}_{\mathrm{y}}$, and $\mathrm{k}_{\mathrm{z}}$ are the thermal conductivities in the $\mathrm{x}, \mathrm{y}$ and $\mathrm{z}$ directions, respectively, $\rho$ is density, $\mathrm{Cp}$ is specific heat, and $v$ is the relative speed of the heat source. The thermal conductivity and specific heat were considered temperature dependent. The initial condition was defined as $T(x, y, z, 0)=$ $\mathrm{T} 0(\mathrm{x}, \mathrm{y}, \mathrm{z})$, while the boundary conditions were defined as the followings [9]:

$$
\mathrm{k}_{\mathrm{x}} \frac{\partial \mathrm{T}}{\partial \mathrm{x}} \mathrm{nx}+\mathrm{k}_{\mathrm{y}} \frac{\partial \mathrm{T}}{\partial \mathrm{y}} \mathrm{ny}+\mathrm{k}_{\mathrm{z}} \frac{\partial \mathrm{T}}{\partial \mathrm{z}} \mathrm{nz}+\mathrm{qr}+\mathrm{hc}(\mathrm{T}-\mathrm{T} \infty)+\sigma \varepsilon \mathrm{F}\left(\mathrm{T}^{4}-\mathrm{T}_{\mathrm{r}}^{4}\right)=0
$$

In equation (2) nx, ny, and $\mathrm{nz}$ are direction cosines of the outward drawn normal to the boundary, qr is the boundary heat flux, hc is the convective heat transfer coefficient, $\sigma$ is Stefan-Boltzmann constant, $\varepsilon$ is emissivity, and $\mathrm{F}$ is the configuration factor. The radiation heat exchange can be treated as convection, expressed by the following (equation 3) equivalent heat transfer coefficient.

$$
\mathrm{h}_{\mathrm{r}}=\sigma \varepsilon \mathrm{F}\left(\mathrm{T}^{2}-\mathrm{T}_{\mathrm{r}}^{2}\right)\left(\mathrm{T}-\mathrm{T}_{\mathrm{r}}\right)
$$




\section{The heat source model}

In the present analysis, to represent the heat generated by the torch in the GTAW process, a moving heat source is developed based on the Goldak model. An important feature in this model is that a double ellipsoid energy is distributed by two ellipsoidal regions, one ahead and one after the weld torch. The power density distribution inside the front quadrant is determined using the following equation (4) [10-11].

$$
\mathrm{q}_{\mathrm{f}}(\mathrm{x}, \mathrm{y}, \mathrm{z})=\frac{6 \sqrt{3} \mathrm{Q} f_{f}}{\mathrm{ab} c_{f} \pi \sqrt{\pi}} \exp \left(\frac{-3 x^{2}}{a^{2}}+\frac{-3 y^{2}}{b^{2}}+\frac{-3[\mathrm{z}+\mathrm{v}(\tau-\mathrm{t})]^{2}}{c^{2} f}\right)
$$

In the same way, the power density distribution for the rear quadrant of the source inside the ellipsoid is determined by the equation (5) [10-11].

$$
\mathrm{q}_{\mathrm{x}}(\mathrm{x}, \mathrm{y}, \mathrm{z})=\frac{6 \sqrt{3} \mathrm{Q} f_{r}}{\mathrm{ab} c_{r} \pi \sqrt{ } \pi} \exp \left(\frac{-3 x^{2}}{a^{2}}+\frac{-3 y^{2}}{b^{2}}+\frac{-3[\mathrm{z}+\mathrm{v}(\tau-\mathrm{t})]^{2}}{c^{2} r}\right)
$$

The energy input rate or heat input is $\mathrm{Q}=\mathrm{VI}$ and where $\mathrm{Q}$ is the $\operatorname{arc}$ efficiency, $\mathrm{v}$ is arc voltage, $\mathrm{I}$ is arc current, $\mathrm{V}$ is the welding speed and $\tau$ is the incubation time. The energy deposited in the front and rear quadrants is defined by the fractions $f_{f}$ and $f_{r}$ where $f_{f}+f_{r}=2$. The variables $a, b, c_{f}$ and $c_{r}$ are the shape parameters determining the shape and size of the weld pool. In this work, depth and width of the weld pool were experimentally measured from the micrographs, when the values of $c_{f}$ and $c_{r}$ were estimated based on the ellipsoid shape of the weld pool. Hence, the values of $a, b$ and $c$ were considered as 2,2 and $4 \mathrm{~mm}$ for the root pass and 2,2 and $6 \mathrm{~mm}$, respectively. These values were consistent with the data reported in literature. The main source was moving along the weld center line, element by element, whose speed was depending on the welding speed. Time increments were automatically optimized for each time step by the computer program. The modified Newton-Raphson method was used in each time step for the heat balance iteration.

\section{SIMULATION MODEL}

In this work, a finite element model was developed using COMOSL Multiphysics similar to the plate dimension $200 \times 100 \times 25 \mathrm{~mm}$ used for experimentation. The objective of this work is to study thermal history of welding process and its validation with experiments. The material properties were fed to the model as given in Table 2. A thermal time-dependent (transient analysis) model was opted for simulation. The bead preparation was also neglected during the study.

\section{Geometry and meshing}

A 3D model of two plates each $200 \times 100 \times 25$ $\mathrm{mm}$ was created in COMSOL. Since it is vital to get accurate simulation model, the type of element chosen for meshing becomes important.

The center part of mesh model was chosen as the weld path which was along the x-direction. The weld region and heat affected zone exhibited high heat flux and temperature and microstructural changes, which were target zones of study. Hence fine meshing was employed in this region.
Fine meshing was done up to $10 \mathrm{~mm}$ on either side of weld path. The other zone represents unaffected region of base metal, hence coarse meshing was used to save computational time.

The accuracy of any simulation model relies on quality of meshing. Initially, simulations were performed with coarse meshing. After convergence, it was found that the results were unacceptable as compared to experimental results. Hence mesh refinement was performed until the results were independent of mesh quality and the solution was acceptable. This mesh was finalized for the simulation work. COMSOL provides three dimensional meshing with sweep function. Initially top surface of the plates was meshed as shown in Figure 3. The 0 and 1 in the legend indicate fine and coarse meshing respectively. Later, surface mesh was swept for the entire three dimensional surface. A complete mesh was consisted of 16420 prism elements, 6568 triangular elements and 350 quadrilateral elements.

\section{Boundary Conditions}

The nodes of all faces were constrained to move in all directions. For thermal analysis, a linear Beizer's polygon was drawn at mating surface 

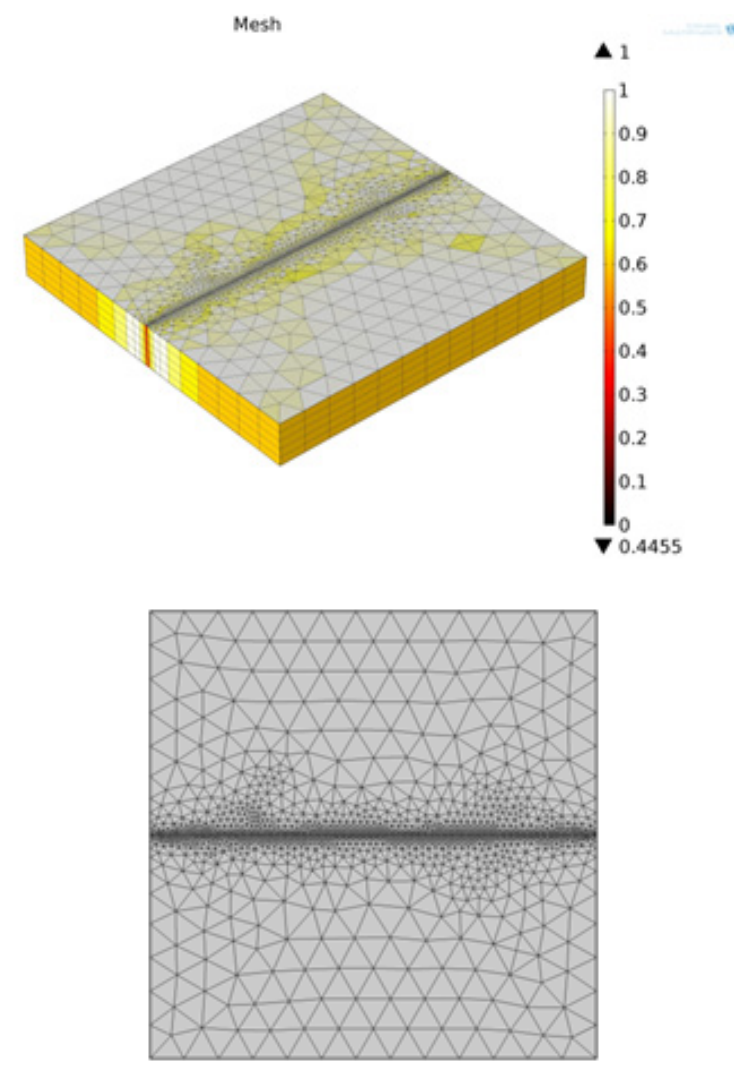

Fig. 3. Meshing of parts

of two parts. This line acts as weld path during simulation where inward heat flux was given as input. All the faces had an interaction with surroundings. Hence heat loss due to conduction, convection and surface to ambient radiation was considered. The thermal boundary conditions are shown in Figure 4.

\section{Simulation}

Equation-based modeling in Heat transfer module under COMSOL Multiphysics is utilized to introduce the developed heat source equations in the FE model for simulating the plasma arc welding on titanium sheets. This enables the use of timedependent loads and sources during the process. A time dependent nonlinear heat transfer analysis is run by applying initial and natural boundary conditions to simulate the temperature distribution profiles for predicting the weld bead geometry.

\section{RESULTS AND DISCUSSION}

\section{Nodal temperature}

The temperature distribution during simulation is shown in Figure 5. The temperature dis-

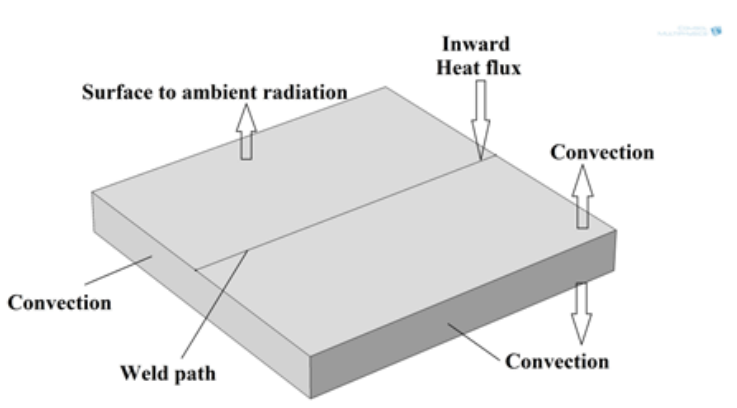

Fig. 4. Boundary Conditions

tribution was plotted along the weld path. The total welding time was $120 \mathrm{~s}$. The maximum temperature during welding was found to be $3568{ }^{\circ} \mathrm{C}$. At the end of the welding process due to arc concentration the temperature obtained was $4225^{\circ} \mathrm{C}$.

Figure 6 shows the temperature distribution in width direction on the work piece from the weld centerline which showed that the arc follows the Gaussian distribution. The temperature distribution is shown from time 55-65 sec at center of the plate. The peak temperature was seen at the weld centerline and along the transverse direction the temperature was getting reduced and attained ambient temperature at a distance of $20 \mathrm{~mm}$. The highest temperature was attained at $60 \mathrm{sec}$, when arc was at the top of the center point of the plate. The half width of the molten pool was observed to be $10 \mathrm{~mm}$. The temperature distribution across the width at different time level is shown in Figure 5.

Figure 7 shows the temperature gradient along the thickness direction. The temperature at the top of the plate was observed to be $3568{ }^{\circ} \mathrm{C}$. The liquidus temperature of the AA2219 was $643{ }^{\circ} \mathrm{C}$. Only a distance upto $8-10 \mathrm{~mm}$ from the top of the plate was maintained above $643{ }^{\circ} \mathrm{C}$ and a molten pool was formed. From the bottom of the plate, only a distance of $8-10 \mathrm{~mm}$ above was heated because of the lack of heat input. Hence partial penetration was obtained and the depth of penetration was observed as $8-10 \mathrm{~mm}$.

Figure 8 shows the temp vs. time curve when the heat source approached the center of plate. As heat source came near to the center of the plate say $\mathrm{t}=50 \mathrm{sec}$, the temperature started rising and attained maximum temperature at $\mathrm{t}=60 \mathrm{sec}$ i.e. center of plate. As time increased i.e. welding arc moved away from center of the plate, the temperature at the center of the plate started decreasing. 

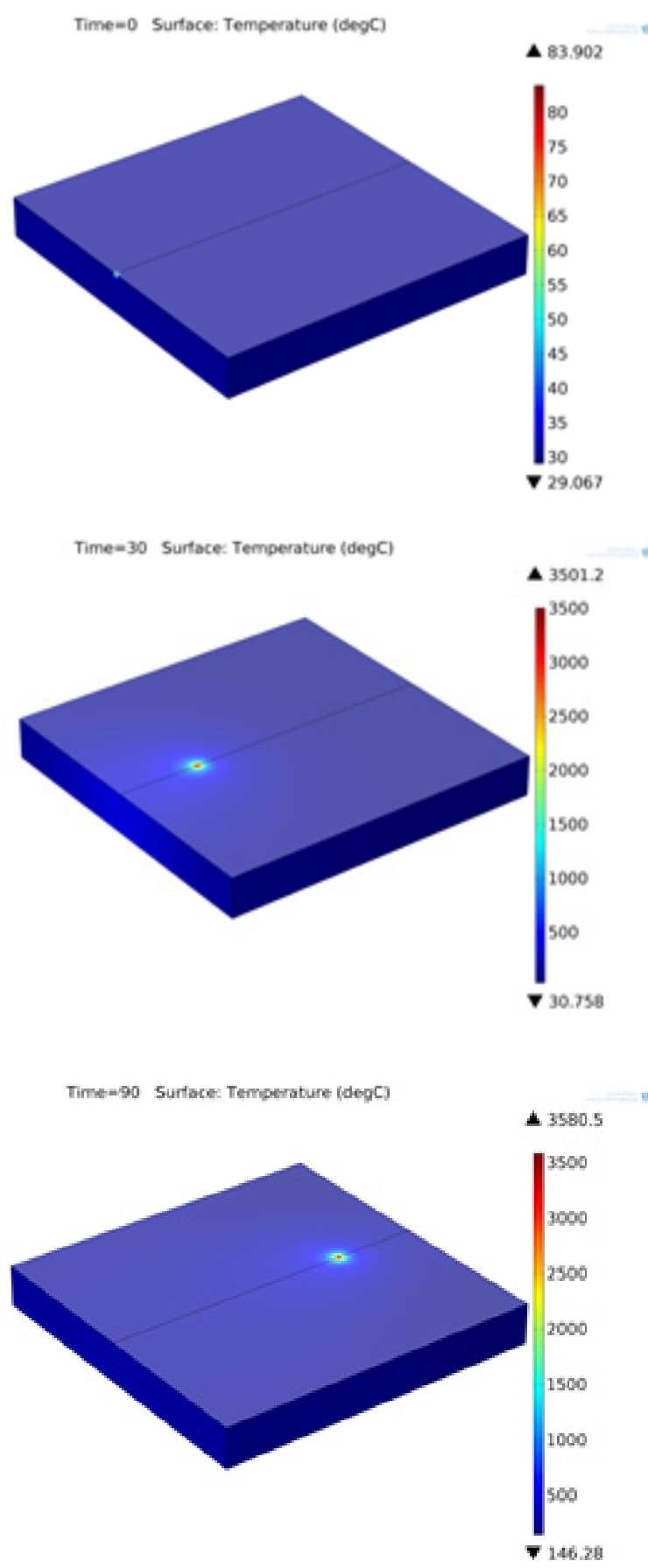
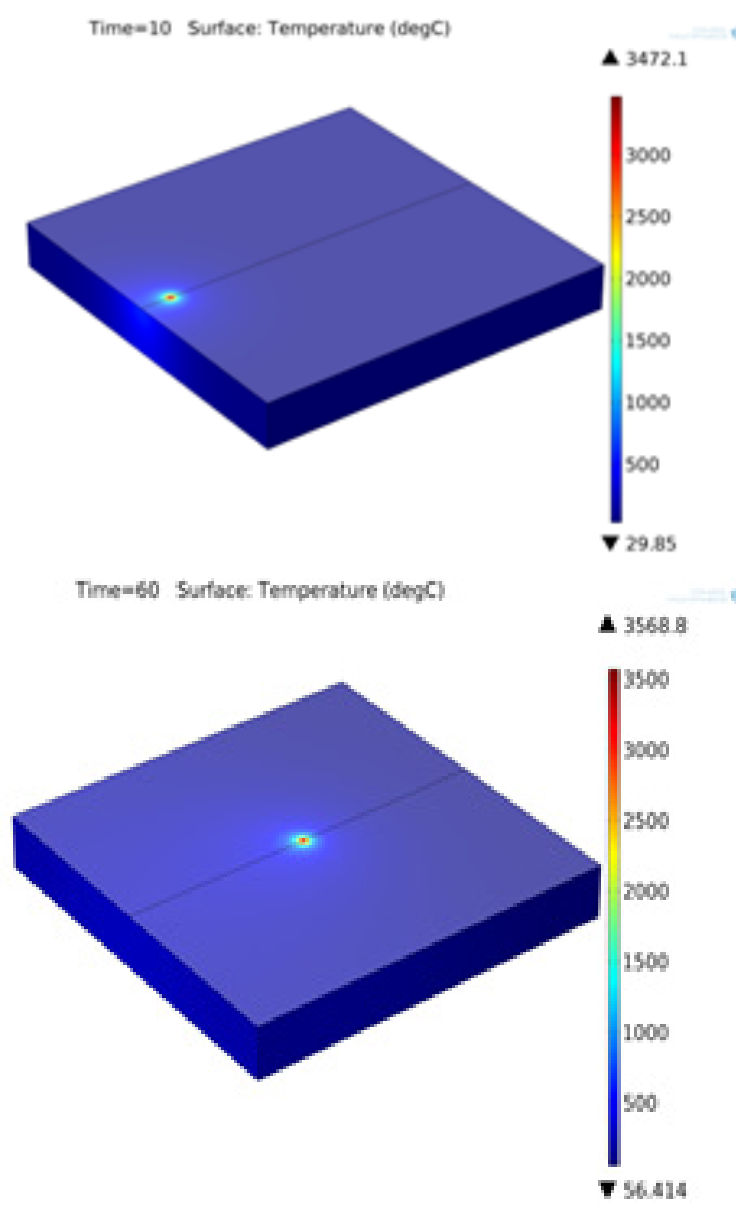

Time-120 Surface: Temperature [degC)

4 4225.1

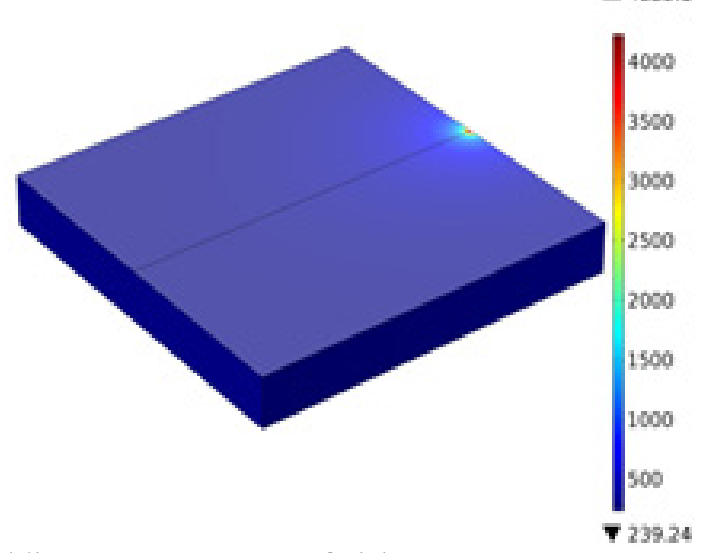

Fig. 5. Temperature profiles of welding process [Start to finish]

\section{Metallurgical characterization}

Typical microstructure of base metal is shown in Figure 9. It is observed from Figure 8 that the copper rich phase was distributed in the aluminium matrix.

The changes in microstructure of GTAW welds is shown in Figure 10. It was revealed from microstructures that the dendrite and reheat refined regions in the multi-pass weld deposition existed. The bright areas represented copper and the dark areas represented aluminium. From Figure 9 , it is also observed that the partial copper rich cellular (CRC) network was in the welds. The weld structure contributed to the improvements in yield strength through the absence of aligned CRC networks [8]. Typical microstructure of HAZ of both the weldments near fusion line is shown in Figure 11.

The distributed copper rich particles act to strengthen the matrix of the weld. The EDS analysis of the weld also indicated the presence 


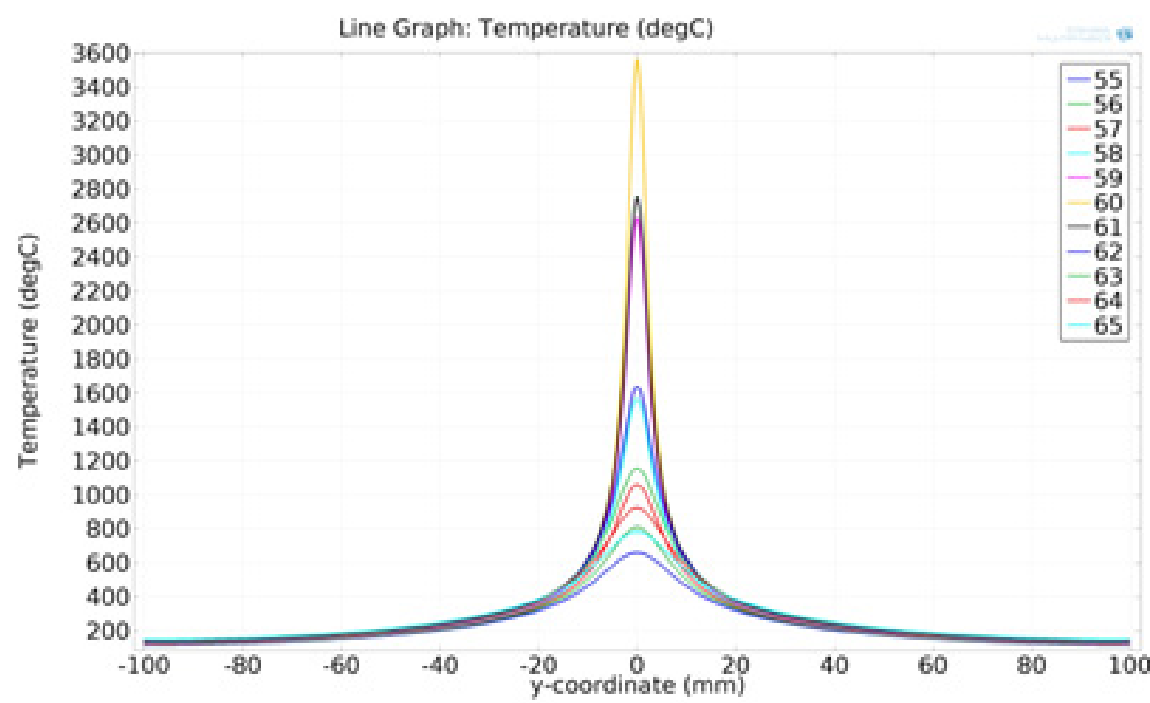

Fig. 6. Temperature distribution across the width at different time

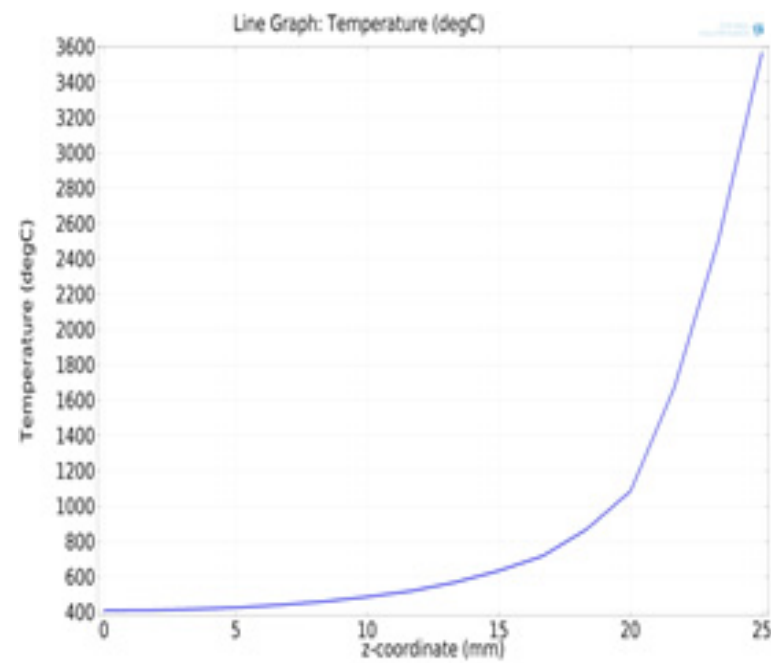

Time $=60$ Surface: Temperature $(\operatorname{deg} C)$

$\boldsymbol{\Delta} 3568.8$

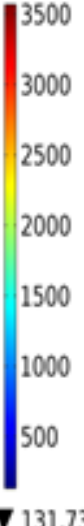

$\mathbf{\nabla} 131.73$

Fig. 7. Temperature distribution across the plate thickness

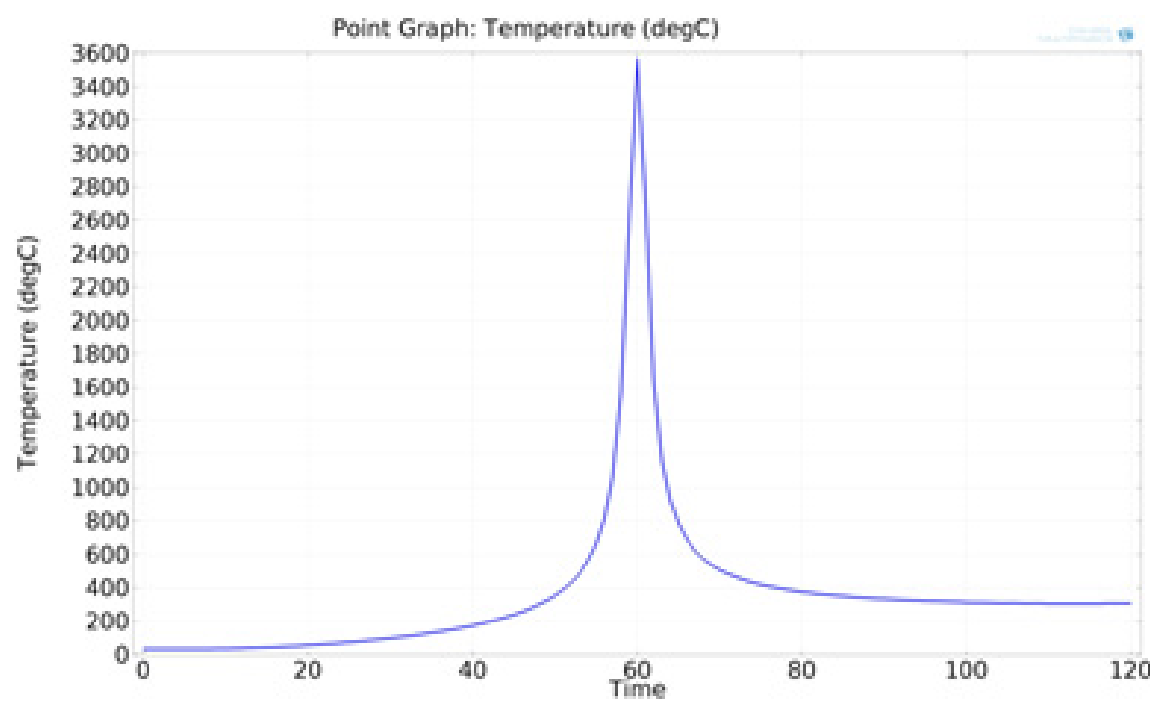

Fig. 8. Time vs temperature curve 
of $\mathrm{CuAl}_{2}$ phase in an aluminium matrix Figure 12. Similar observations were reported in EBW of AA2219 alloy [8]. The chemical composition of the weld deposits are presented in Table 3.

The width of heat affected zone was compared for simulated and experimental results as shown in Figure 13. Table 4 shows length of heat affected zone from weld centerline. It is confirmed that simulated results comply with experimental results. Figure 14 shows the XRD pattern of GTAW welds. It clearly shows that all the peaks

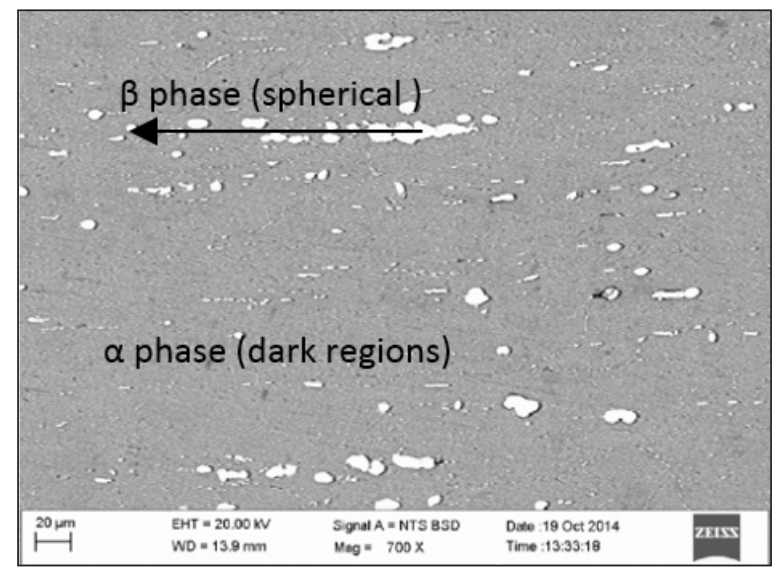

Fig. 9. Base metal microstructure

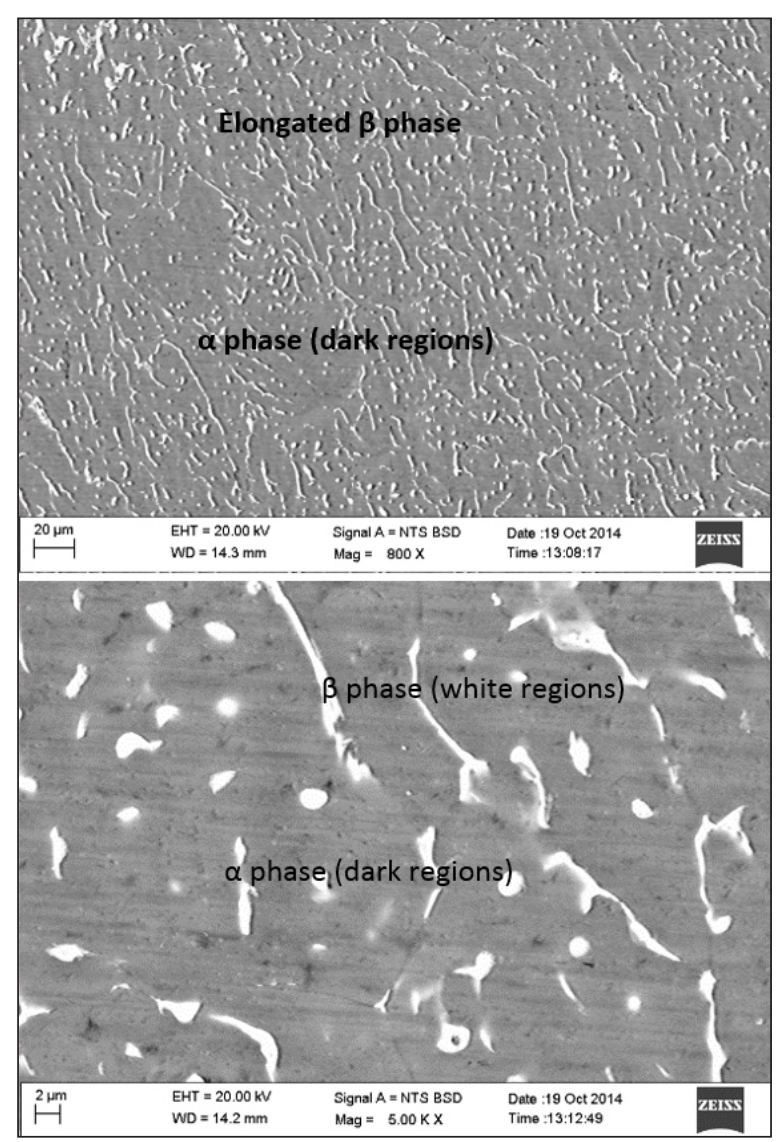

Fig. 10. Typical microstructure of weld joint
Table 3. Chemical composition of weld deposits

\begin{tabular}{|c|c|c|c|c|c|c|}
\hline \multirow{2}{*}{$\begin{array}{c}\text { Weld } \\
\text { deposit }\end{array}$} & \multicolumn{6}{|c|}{ Chemical composition/wt\% } \\
\cline { 2 - 7 } & $\mathrm{Si}$ & $\mathrm{Mn}$ & $\mathrm{Mg}$ & $\mathrm{Fe}$ & $\mathrm{Cu}$ & $\mathrm{Al}$ \\
\hline GTAW & 0.02 & 0.93 & 0.35 & 0.19 & 6.24 & Bal. \\
\hline
\end{tabular}

Table 4. Length of HAZ from weld centerline

\begin{tabular}{|l|c|c|}
\hline \multicolumn{1}{|c|}{ Parameter } & $\begin{array}{c}\text { Simulation } \\
\text { results }\end{array}$ & $\begin{array}{c}\text { Experimental } \\
\text { results }\end{array}$ \\
\hline $\begin{array}{l}\text { Length of heat } \\
\text { affected zone from } \\
\text { weld centerline }\end{array}$ & $12 \mathrm{~mm}$ & $11 \mathrm{~mm}$ \\
\hline
\end{tabular}

were corresponding to the $\mathrm{Al}$ and small amount of intermetallic compounds like $\mathrm{Al}_{2} \mathrm{Cu}$ was observed through the XRD pattern.

The base metal shows beta phase ( $\mathrm{Cu}$ rich) in the matrix and alpha phase (Al rich) it is observed that the beta phase is in the form of nearly spherical shape. Further it is observed from microstructure that beta phase is oriented in the one direction. This is due to rolling. Figure 10 shows the weld zone. It is observed that the beta phase is uniformly distributed in the alpha matrix and the slope of the beta phase has found to be fully elongated. From the micro structure shows that the dendritic of alpha phase. The elongated beta phase in alpha dendrite indicates that modular casting of significant during rolling.

\section{CONCLUSIONS}

Gas tungsten arc welding of AA2219 aluminium alloy was simulated using $3 \mathrm{D}$ finite element model on COMSOL multiphysics softrware. The weld bead geomentries were compared for both

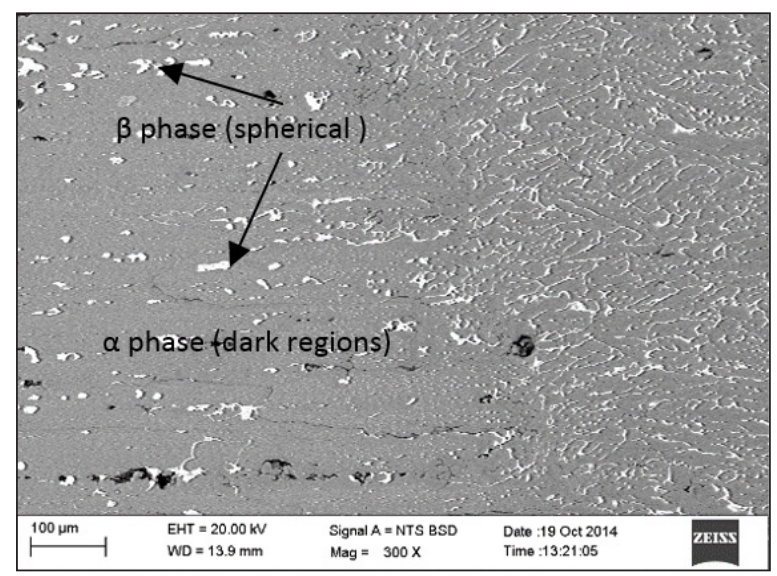

Fig. 11. Typical microstructure of HAZ near to fusion line of weldments 

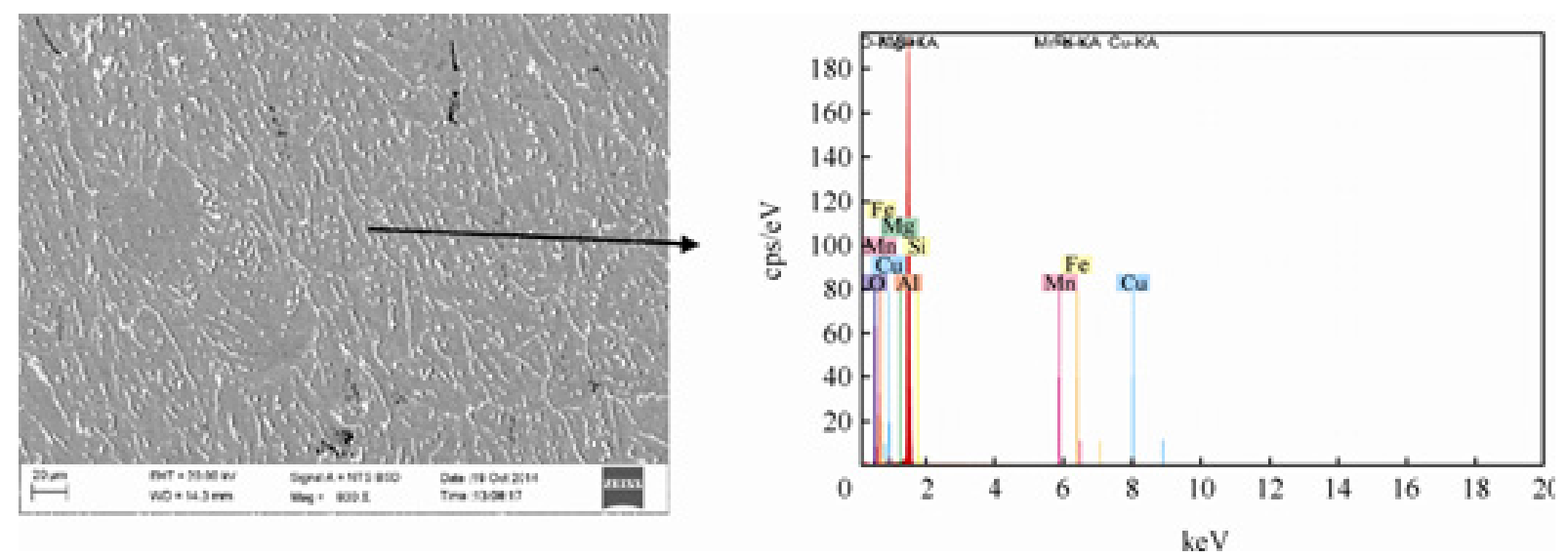

Fig. 12. EDS results of AA2219 weldments

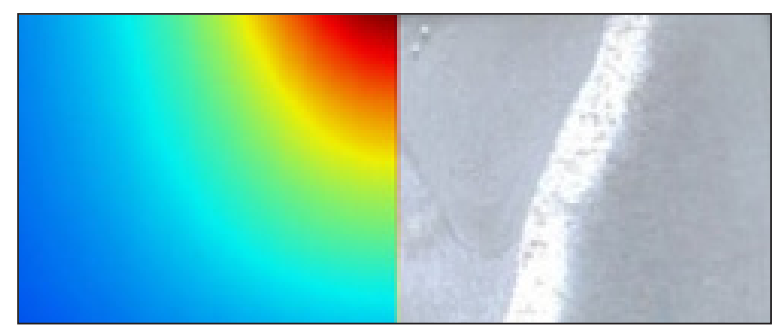

Fig. 13. Experimental and simulated weld bead

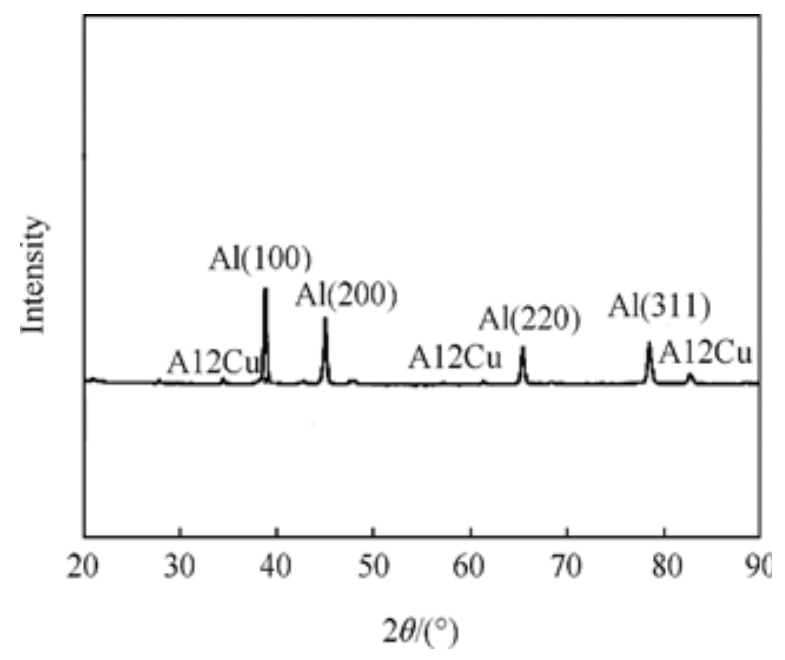

Fig. 14. XRD analysis of weld metal GTAW

experimental and simulated results. The compatibility of COMSOL software for welding simulations was perceived. The following conclusions were drawn from the study.

1. $3568{ }^{\circ} \mathrm{C}$ temperature was observed during welding and the temperature profile was predicted by simulations.

2. Gaussian distribution was observed in the transverse direction of temperature profile.

3. In simulation and experimental the half width of heat affected zone was predicted and the values are $12 \mathrm{~mm}$ and $11 \mathrm{~mm}$. It shows the simulation results were shallow of the experimental results.

4. XRD patterns revealed that Aluminum was a major phase, and a small amount of $\mathrm{Al}_{2} \mathrm{Cu}$ was observed in the weld metal.

\section{Acknowledgements}

We acknowledge Shri P.Sankaravelayutham, Dy. General Manager, MMD/MME, VSSC, ISRO, Thiruvanandhapuram-695022 to provide the base material and WRI, BHEL, Trichy, Tamilnadu to carry out the welding trials.

\section{REFERENCES}

1. Hartman J.A., Beil R.J. and Hahn G.T.: Effect of copper rich regions on tensile properties of VPPA weldments of 2219-T87 aluminuim, Welding Research Supplement, 66, 1987, 73-83.

2. Nair B.S.., Rakesh S, Phanikumar G., Prasad Rao K, Sinha P.P.: Fracture toughness (J 1C) of electron beam welded AA2219 alloy, Materials \& Design 31 (10), 2010, 4943-4950.

3. Arunkumar S., Rangarajan P., Devakumaran K. and Sathiya P.: Comparative studies on transverse shrinkage, mechanical and metallurgical properties of aa2219 aluminium weld joints by gas tungsten arc and gas metal arc welding processes, Defence Technology, 11, 2015, 262-268.

4. Malarvizhi S., Balasubramanian V.: Effect of welding processes on AA2219 aluminium alloy joint properties, Trans. Nonferrous met. Soc. China 21, 2011, 962-973.

5. Andrés Anca, Alberto Cardona, José Risso, Víctor, Fachinotti D.: Finite element modeling of welding processes, Applied Mathematical Modelling 35, 2011, 688-707. 
6. Gonçalves C.V., Vilarinho L.O., Scotti A., and Guimarães G.: Estimation of heat source and thermal efficiency in GTAW process by using inverse techniques, Journal of Materials Processing Technology, 172, 2006, 42-51.

7. Salehi Yegaie Y., Kermanpur A., Shamanian M.: Numerical simulation and experimental investigation of temperature and residual stresses in GTAW with a heat sink process of Monel 400 plates, Journal of Materials Processing Technology 210, 2010, 1690-1701.

8. Gupta R.K., Ghosh B.R., Biju S., Sinha P.P.: Welding research supplement-GTAW process design for improved weld strength of AA2219, Australasian Welding Journal 54 (2), 2009, 37-48.

9. Ilegbusi O.J., Iguchi M., Wahnsiedler W.: Mathematical and Physical Mod-elling of Materials Processing Operations. Chapman \& Hall/CRC, 2000.

10. Goldak J., Chakravarti A., Bibby M.: A new finite element model for welding heat sources. Metall.
Trans. B 15, 1984, 299-305.

11. Goldak J., Akhlaghi M.: Computational Welding Mechanics. Springer Science Business Media, New York, 2005, 29-34.

12. Aissani Sofiane Guessasma, Abdelhalim Zitoun, Rabah Hamzaoui, David Bassir, Younes Benkedda: Three-dimensional simulation of 304L steel TIG welding process: Contribution of the thermal flux Mouloud. Applied Thermal Engineering 89, 2015, 822- 832.

13. Abid M., Parvez S., Nash D.H.: Effect of different electrode tip angles with tilted torch in stationary gas tungsten arc welding: A 3D simulation, International Journal of Pressure Vessels and Piping 108-109, 2013, 51-60.

14. Zhang Tong, Zheng Zhentai, Zhao Rui: A dynamic welding heat source model in pulsed current gas tungsten arc welding. Journal of Materials Processing Technology 213, 2013, 2329-2338. 